\title{
The Efficacy of Posttreatment with Synthetic C-Reactive Protein in Murine Bacterial Peritonitis via Activation of FcyRI-Expressing Kupffer Cells
}

\author{
Manabu Kinoshita ${ }^{a}$ Seigo Ito $^{b}$ Takuya Ishikiriyama ${ }^{a}$ Kumiko Sekiguchi $^{c}$ \\ Ryota Yamaguchid $^{d}$ Ryoichi Tsuruhara ${ }^{d}$ Akihisa Matsuda ${ }^{c}$ Kazuki Koiwa ${ }^{a}$ \\ Masahiro Nakashima ${ }^{a}$ Hiroyuki Nakashima ${ }^{a}$ Masao Miyashita ${ }^{c}$ Shuhji Seki ${ }^{a}$ \\ aDepartment of Immunology and Microbiology, National Defense Medical College, Tokorozawa, Saitama, Japan; \\ ${ }^{b}$ Department of Nephrology and Endocrinology, National Defense Medical College, Tokorozawa, Saitama, Japan; \\ 'Department of Surgery, Nippon Medical School Chiba Hokusoh Hospital, 1715 Kamagari, Inzai, Chiba, Japan; \\ ${ }^{\mathrm{d}}$ Medical Student, National Defense Medical College, Tokorozawa, Saitama, Japan
}

\section{Keywords}

Cecal ligation and puncture - Liver macrophages .

Phagolysosomal activity

\section{Abstract}

Pretreatment with synthetic C-reactive protein (CRP), a functional CRP peptide, has the potential to augment macrophage phagocytosis by bacterial challenge. However, the posttreatment is clinically ideal. We investigated the efficacy of posttreatment with synthetic CRP on murine cecal ligation and puncture (CLP), focusing on liver macrophages. Mice received CLP, and $1 \mathrm{~h}$ later, synthetic CRP or saline was intraperitoneally administered. Posttreatment with synthetic CRP increased the murine survival after CLP. It reduced viable bacterial counts in the liver $24 \mathrm{~h}$ after CLP with an increase in the number of Kupffer cells but not monocyte-derived liver macrophages. Posttreatment with synthetic CRP increased the phagolytic activity of Kupffer cells against Escherichia coli (E. coli) as well as capsulated Klebsiella pneumoniae at $3 \mathrm{~h}$ after CLP. Synthetic CRP therapy augmented TNF production by E. coli-phagocytosing Kupffer cells, resulting in an increase in tissue TNF levels in the liver at $24 \mathrm{~h}$. Kupffer cells substantially expressed FcyRl, which is a ligand of $\mathrm{CRP}$, and their $\mathrm{Fc} \mathrm{RI}$ expression was further increased after CLP. In contrast, synthetic CRP therapy affected neither the phagocytic function of monocyte-derived liver macrophages (showing a weak FcyRI expression) nor their TNF production. Depletion of Kupffer cells in mice inhibited these beneficial effects of synthetic CRP in CLP mice. Conclusion: Posttreatment with synthetic CRP effectively improves murine bacterial peritonitis via the activation of phagocytosis of $\mathrm{Fc \gamma Rl}$-expressing Kupffer cells.

(C) 2021 The Author(s).

Published by S. Karger AG, Basel

\section{Introduction}

Bacterial elimination by macrophages is crucial for the host defense against sepsis/severe infections. Accordingly, the augmentation of bactericidal activity of macrophages may be an ideal therapeutic strategy for septic patients, particularly immunocompromised hosts [1]. In this respect, the liver is a key organ for the host defense against bacterial infection [2]. However, severe bactere-
C 2021 The Author(s).

Published by S. Karger AG, Basel

This is an Open Access article licensed under the Creative Commons Attribution-NonCommercial-4.0 International License (CC BY-NC) (http://www.karger.com/Services/OpenAccessLicense), applicable to the online version of the article only. Usage and distribution for commercial purposes requires written permission.
Correspondence to:

Manabu Kinoshita, manabu@ndmc.ac.jp 
$\mathrm{mia} /$ sepsis may overcome the bacterial clearance activity of the liver [3].

C-reactive protein (CRP), originally named for its capacity to precipitate the somatic C-polysaccharide of Streptococcus pneumoniae, is an acute-phase protein mainly produced by hepatocytes in response to infection and/or tissue damage [4]. CRP and synthetic CRP, which is a functional CRP peptide, have positive and regulatory effects on innate immunity against bacterial infection and tumors [4-7]. CRP is also well-known as an opsonizing factor that is important in the defense against capsulated bacteria [4]. We previously reported that pretreatment with synthetic CRP increased the survival rate after lethal intravenous Escherichia coli (E. coli) challenge in mice because CRP augmented the bactericidal activity of liver macrophages [6]. Although phagocytosis by macrophages and their proinflammatory cytokine production are basically synchronized [8], synthetic CRP did not strongly augment the TNF production by macrophages even after bacterial challenge $[6,7]$. Considering the patient care in clinical settings, such unique characteristics of synthetic CRP, namely, enhancing bactericidal activity without increasing proinflammatory cytokine production by macrophages, may be attractive as a therapy for sepsis/ severe infections.

Murine cecal ligation and puncture (CLP) is considered the gold standard in sepsis research, satisfying many of the criteria set by critics listing essential attributes for an appropriate model: it is polymicrobial, has focal infection origins, produces septicemia, and releases bacterial products into the periphery [9]. In the clinical setting, essentially all therapies for septic patients must be started after the onset of the infection. Therefore, we investigated the efficacy of posttreatment of synthetic CRP on murine CLP, focusing on liver macrophages.

Liver macrophages can be classified into tissue-resident macrophages, namely, Kupffer cells, and monocytederived macrophages [10-12], which have been recently found to have ontogenically different origins [13]. Kupffer cells have a potent phagocytic activity, while monocytederived macrophages have a potent TNF-producing capability [10-12]. Since our previous study was conducted before the establishment of the 2 Kupffer cells/macrophages concept, we were unable to precisely investigate the effect of synthetic CRP on these 2 subsets [6]. Therefore, the current study demonstrated which types of macrophages are mainly affected by synthetic CRP posttreatment in CLP mice.

Posttreatment with Synthetic CRP for Murine Bacterial Peritonitis

\section{Materials and Methods}

\section{CLP Procedure}

Male C57BL/6 mice were used (8 weeks old, 20 g; Japan SLC, Shizuoka, Japan). CLP was aseptically performed, as described previously $[14,15]$. In brief, the mice were anesthetized with isoflurane. After shaving their anterior abdominal wall, a small incision was made to expose the cecum, which was ligated just below the ileocecal valve with 3.0 silk. Subsequently, the cecum was punctured once with a 21-gauge needle, and approximately $1 \mathrm{~mm}$ of feces was extruded and then wiped up. Thereafter, the injured cecum was placed back into the abdominal cavity, followed by abdominal closure.

\section{Posttreatment with Synthetic CRP}

Synthetic CRP peptide (174-185) was purchased from BACHEM (King of Prussia, PA, USA) [6, 7]. The mice were intraperitoneally injected with 20 or $10 \mathrm{mg} / \mathrm{kg}$ of synthetic CRP diluted with $1 \mathrm{~mL}$ saline or injected with $1 \mathrm{~mL}$ saline alone (as a control) at $1 \mathrm{~h}$ or $3 \mathrm{~h}$ after CLP.

Viable Bacterial Count in the Peritoneal Lavage Fluid, Blood, and Liver

We examined the viable bacterial counts as previously described $[6,15-17]$. In brief, under deep isoflurane anesthesia, $1 \mathrm{~mL}$ of saline was injected into the murine peritoneal cavity, and then $0.5 \mathrm{~mL}$ of lavage fluid was aseptically collected. A blood sample (1 $\mathrm{mL}$ ) was also aseptically withdrawn from the abdominal vena cava. The liver was aseptically removed to produce a homogenized PBS suspension. Thereafter, each bacterial suspension was diluted serially 10-fold in PBS, plated on brain heart infusion agar plates, and incubated overnight at $37^{\circ} \mathrm{C}$. The number of viable bacteria was then counted according to the observed colonies on the agar plates.

\section{Isolation of PECs and Liver MNCs}

As described previously $[6,16,17]$, mononuclear cells (MNCs) were isolated from the peritoneal exudate and liver. In brief, the peritoneal lavage fluid $(0.5 \mathrm{~mL})$ was obtained as described above. The liver was also aseptically obtained and minced with scissors. After shaking with $10 \mathrm{~mL}$ Hank's balanced salt solution containing 0.05\% collagenase (type IV; Sigma-Aldrich, St Louis, MO, USA) for $20 \mathrm{~min}$ at $37^{\circ} \mathrm{C}$, liver specimens were filtered through the mesh, suspended in $33 \%$ Percoll $^{\circledR}$ solution (Sigma-Aldrich) containing $10 \mathrm{U} / \mathrm{mL}$ heparin, and centrifuged for $15 \mathrm{~min}$ at $500 \mathrm{~g}$ at room temperature. To obtain the peritoneal exudate cells (PECs) and liver MNCs, the cells were treated with a red blood cell lysis solution and washed twice.

A Flow Cytometric Analysis of Peritoneal Macrophages,

Kupffer Cells, and Monocyte-Derived Liver Macrophages and the Evaluation of the Fc $\gamma R I$ Expression

After incubation with the Fc-blocker (2.4 G2; BD Pharmingen, San Diego, CA, USA), PECs or liver MNCs were stained with FITC-conjugated anti-F4/80 Ab (BM8; eBioscience, San Diego, CA, USA), PE-Cy5-conjugated anti-CD11b Ab (M1/70; eBioscience), and APC-conjugated anti-CD45 Ab (30-F11; eBioscience). To examine the $\mathrm{Fc} \gamma$ receptor I $(\mathrm{Fc} \gamma \mathrm{RI})$ expression, MNCs were stained with PE-conjugated anti-Fc $\gamma$ RI (CD64) (X54-5/7.1.1; BD Pharmingen). MNCs were also stained with respective isotype Abs as isotype controls. A 4-color flow cytometric analysis was per- 
formed using a flow cytometer (ACEA Biosciences, San Diego, CA, USA). Peritoneal macrophages were $\mathrm{CD} 45^{+}$and $\mathrm{F} 4 / 80^{+} \mathrm{CD} 11 \mathrm{~b}^{+}$, Kupffer cells were CD $45^{+}$and F $4 / 80^{\text {high }} \mathrm{CD} 11 \mathrm{~b}^{\text {low }}$, and monocytederived liver macrophages were $\mathrm{CD} 45^{+}$and $\mathrm{F} 4 / 80^{\text {low }} \mathrm{CD} 11 \mathrm{~b}{ }^{\text {high }}$, according to previous studies $[17,18]$. Regarding the PECs, cells were stained with PE-conjugated anti-Ly6G Ab (1A8-Ly6g; eBioscience) to detect neutrophils. PECs were further stained with APC-conjugated anti-Ly6C Ab (HK1.4; eBioscience) to detect tissue-resident $\left(\mathrm{Ly}_{6 \mathrm{C}^{-}} \mathrm{Ly}_{6 \mathrm{G}}^{-} \mathrm{F} 4 / 80^{\text {high }} \mathrm{CD} 11 \mathrm{~b}^{+}\right)$or monocyte-derived $\left(\mathrm{Ly}_{6 \mathrm{C}} \mathrm{L}^{+} 6 \mathrm{G}^{-} \mathrm{F} 4 / 80^{\text {low }} \mathrm{CD} 11 \mathrm{~b}^{+}\right.$) macrophages.

Digestion of pHrodo-Conjugated E. coli by PECs, Kupffer Cells, or Monocyte-Derived Liver Macrophages

To examine the digestive activity of $E$. coli by macrophages, PECs or liver MNCs were incubated with $1 \mathrm{mg} / \mathrm{mL}$ of pHrodo (acidic pH-dependent fluorescence)-conjugated E. coli (BioParticles $^{\circledR}$; Invitrogen Life Technologies, Carlsbad, CA, USA) for $1 \mathrm{~h}$ at $37^{\circ} \mathrm{C}$ or $4^{\circ} \mathrm{C}$ (as a negative control) [17], using the temperatureresponsive cell culture plates $\left(\mathrm{UpCell}^{\circledR}\right.$; CellSeed Inc., Tokyo, Japan) [19]. Acidification of phagolysosomes following the ingestion of $E$. coli in PECs, Kupffer cells (CD $\left.45^{+} \mathrm{F} 4 / 80^{\text {high }} \mathrm{CD} 11 \mathrm{~b}^{\text {low }}\right)$, or monocyte-derived liver macrophages $\left(\mathrm{CD} 45^{+} \mathrm{F} 4 / 80^{\text {low }} \mathrm{CD} 11 \mathrm{~b}^{\text {high }}\right)$ was analyzed using flow cytometry. Regarding in vitro stimulation with synthetic CRP, PECs obtained from the mice $1 \mathrm{~h}$ after CLP were incubated with $0.2 \mathrm{mg} / \mathrm{mL}$ of synthetic CRP, and subsequently, pHrodo-conjugated $E$. coli were added to the incubated cells. After 1-h incubation, the phagolysosomal acidification of PECs was analyzed.

\section{Digestion of pHrodo-Conjugated Capsulated K. pneumoniae}

by Kupffer Cells or Monocyte-Derived Liver Macrophages

We examined the effect of CRP treatment on the in vitro digestive activity of Klebsiella pneumoniae (K. pneumoniae), which are capsulated enterobacteria. We intraperitoneally inoculated 2 mice with $K$. pneumoniae $\left(5 \times 10^{8} \mathrm{CFU}\right)$, which were kindly provided from the culture stock of the Department of Bacteriology, Kyushu University [20], and harvested them $24 \mathrm{~h}$ later. After confirmation of their capsule synthesis (see online suppl. Fig 1; for all online suppl. material, see www.karger.com/doi/10.1159/000515333), capsulated K. pneumoniae $\left(2 \times 10^{10} \mathrm{CFU}\right)$ were stained with pHrodo dye ${ }^{\circledR}$ Red, SE (Invitrogen Life Technologies) according to the manufacturer's instructions. Thereafter, liver MNCs obtained from mice $3 \mathrm{~h}$ after CLP were incubated with $0.1 \mathrm{mg} / \mathrm{mL}$ of pHrodo-conjugated capsulated K. pneumoniae for $1 \mathrm{~h}$ at $37^{\circ} \mathrm{C}$ or $4^{\circ} \mathrm{C}$ (as a negative control).

The Analysis of Intracellular TNF in E. coli-Phagocytosing Kupffer Cells or Monocyte-Derived Liver Macrophages

Liver MNCs were obtained from the mice at $3 \mathrm{~h}$ after CLP $(2 \mathrm{~h}$ later CRP treatment) and incubated with pHrodo-conjugated $E$. coli for $1 \mathrm{~h}$ using temperature-responsive culture plates $\left(\mathrm{UpCell}^{\circledR}\right)$. During the incubation, BD GoldiStop ${ }^{\circledR}(0.7 \mu \mathrm{g} / \mathrm{mL}$; BD PharMingen) was added to incubated cells. Thereafter, the cells were stained with PE-Cy5-conjugated anti-F4/80 Ab (BM8; eBioscience) and APC-conjugated CD11b Ab (M1/70; eBioscience), followed by incubation with BD Cytofix/Cytoperm solution ${ }^{\circledR}$ (BD PharMingen) for 20 min. After washing with BD Permwash solution ${ }^{\circledR}$ (BD PharMingen), the cells were stained with FITC-conjugated antiTNF Ab (MP6-XT22; eBioscience) or isotype Rat IgG1K (eBioscience). After washing, the phagolysosomal acidification of ingested
E. coli in Kupffer cells or monocyte-derived liver macrophages and their intercellular TNF were analyzed using flow cytometry.

Depletion of Kupffer Cells by Clodronate Liposome in Mice

To examine the effect of depletion of Kupffer cells on synthetic CRP treatment in CLP mice, $0.2 \mathrm{~mL}$ of clodronate liposomes (Clophosome- $\mathrm{A}^{\circledR}$; FormuMax Scientific Inc., Sunnyvale, CA, USA) was intravenously administered to mice, as described previously $[11,17]$. Two days later, the mice received CLP followed by CRP or saline treatment. We also intravenously administered $0.2 \mathrm{~mL}$ of clodronate liposomes to mice, and 2 days later, CLP was performed to examine the effect of clodronate treatment on the PECs in mice at $24 \mathrm{~h}$ after CLP.

The Measurement of Cytokines and ALT in the Liver Tissue, Peritoneal Lavage Fluid, or Plasma

Samples of the liver, peritoneal lavage fluid, and blood were obtained from the mice in the same manner as for the bacterial quantification. After centrifugation at $400 \mathrm{~g}$ for $15 \mathrm{~min}$, supernatants of liver homogenates were collected and stored at $-80^{\circ} \mathrm{C}$ until assay. TNF, IFN- $\gamma$, and IL-12 levels in the supernatant, lavage fluid, and plasma were measured using cytokine-specific enzymelinked immunosorbent assay kits (Invitrogen Life Technologies). Plasma alanine aminotransferase (ALT) levels were measured using the Fuji Dri-Chem system (Fuji Film, Tokyo, Japan). Tissue cytokine levels are expressed as a relative value to a given protein concentration (per $1 \mathrm{mg}$ tissue protein).

\section{Statistical Analyses}

Statistical analyses were performed using the StatView 4.02J software package (Abacus Concepts, Berkeley, CA, USA). Data are expressed as the mean values \pm standard errors. The survival rates were compared using Wilcoxon's rank test, and other statistical evaluations were performed using a one-way analysis of variance followed by the Bonferroni post hoc test among 3 groups or unpaired Student's $t$ test between 2 groups. $p<0.05$ was considered to indicate a significant difference.

\section{Results}

\section{Posttreatment with Synthetic CRP Increased the}

\section{Survival of CLP Mice}

Posttreatment with $20 \mathrm{mg} / \mathrm{kg}$ of synthetic CRP at 1 $\mathrm{h}$ after CLP significantly increased murine survival in comparison with the control mice (70 vs. $10 \%, p<$ 0.01 ) (Fig. 1a). Posttreatment with $10 \mathrm{mg} / \mathrm{kg}$ of synthetic CRP also showed a $40 \%$ survival rate, suggesting that posttreatment with synthetic CRP dose dependently increased the survival in mice with bacterial peritonitis (Fig. 1a). However, synthetic CRP (20 mg/ $\mathrm{kg})$ treatment at $3 \mathrm{~h}$ after CLP was not effective (20\% survival). Posttreatment with $20 \mathrm{mg} / \mathrm{kg}$ of synthetic CRP at $1 \mathrm{~h}$ after CLP dramatically reduced bacterial counts in the peritoneal cavity at $24 \mathrm{~h}$ after CLP while significantly increased the number of PECs at $24 \mathrm{~h}$ 


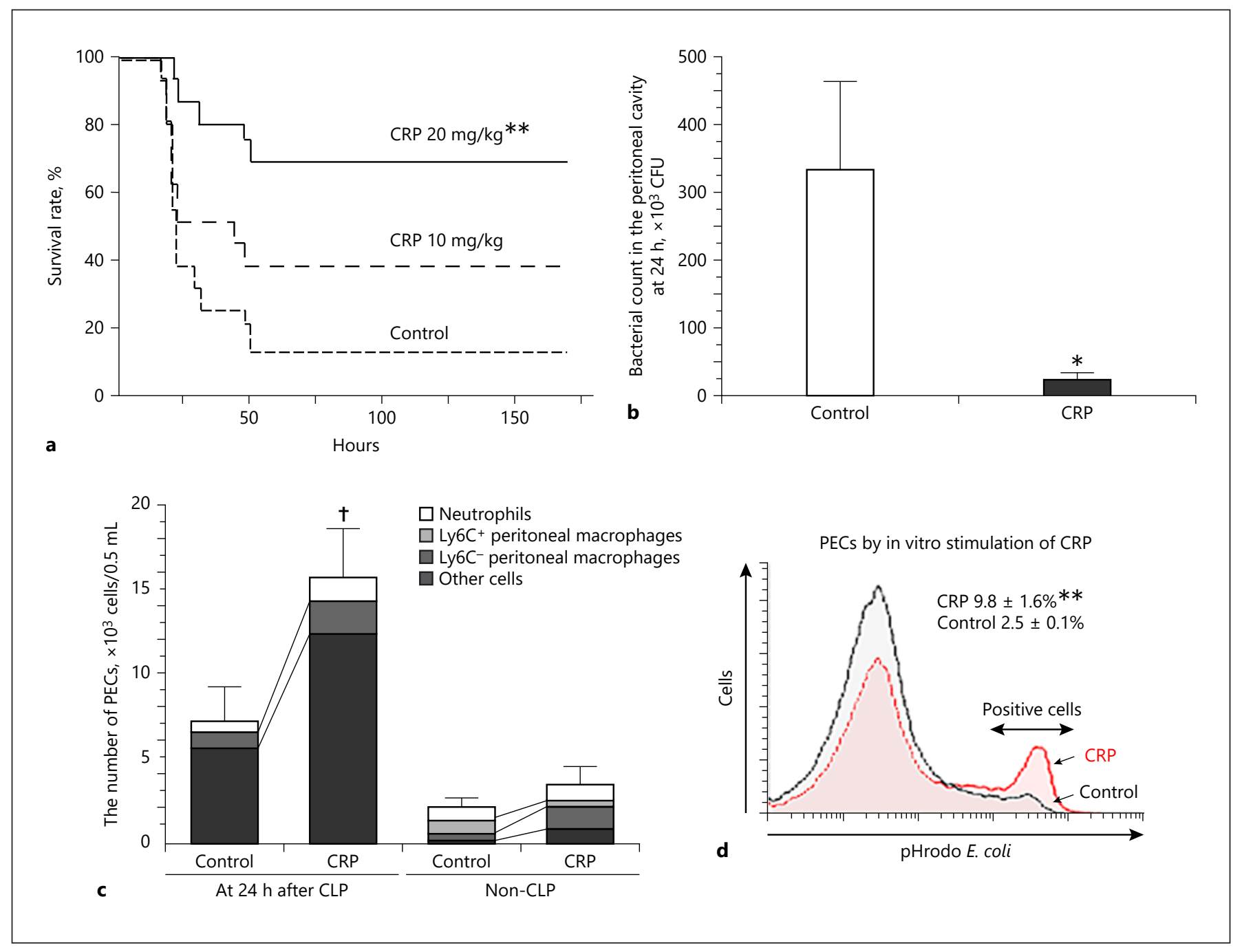

Fig. 1. a The effect of posttreatment with synthetic CRP on the murine survival after CLP. Synthetic CRP (20 or $10 \mathrm{mg} / \mathrm{kg}$ ) or saline (as a control) was intraperitoneally administered into the mice ( $n=16$ in each group) $1 \mathrm{~h}$ after CLP to monitor the survival. The effect of synthetic CRP on the viable bacterial count (b) and the number and cellularity of PECs (c) in the peritoneal cavity at $24 \mathrm{~h}$ after CLP were examined. Synthetic CRP $(20 \mathrm{mg} / \mathrm{kg})$ or saline was intraperitoneally administered to mice at $1 \mathrm{~h}$ after CLP. Thereafter, the bacterial counts in the peritoneal cavity (b) and the number and cellularity of PECs (c) were examined at $24 \mathrm{~h} . N=9$ in each group. PECs were also obtained from the CRP- or saline-treated non-CLP mice $(n=6)$. Neutrophils were $\mathrm{Ly}_{6 \mathrm{G}}{ }^{+} \mathrm{CD} 45^{+}$cells, Ly6C $C^{-}$peritoneal macrophages were ${\text {Ly } 6 C^{-}}^{-}{\text {Ly } 6 G^{-}}^{-}$F4/80 high

(Fig. 1b, c). Nevertheless, cellularity of these increased PECs by CRP treatment was not significantly changed in comparison with the control CLP mice (Fig. 1c). Neutrophils (approximately $80 \%$ ) and $\mathrm{Ly}^{6} \mathrm{C}^{+}$monocyte-derived macrophages (approximately 10\%) were

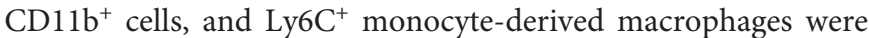
Ly6C $\mathrm{C}^{+} \mathrm{Ly}_{6 \mathrm{G}} \mathrm{F}^{-} \mathrm{F} / 80^{\text {low }} \mathrm{CD} 11 \mathrm{~b}^{+}$cells (c). Data are shown as the mean \pm SE $(\mathbf{b}, \mathbf{c})$. The effect of in vitro stimulation with synthetic CRP on the phagolysosomal activity of PECs (d). PECs obtained from the mice $1 \mathrm{~h}$ after CLP were incubated with or without synthetic CRP $(0.2 \mathrm{mg} / \mathrm{mL})$ and subsequently coincubated with pHrodo $E$. coli for $1 \mathrm{~h}$ to examine their phagolysosomal activity (d). The proportion of positive cells (indicated by bidirectional arrows) shown is the mean \pm SE. Data are pooled from 2 individual experiments with similar results. ${ }^{* *} p<0.01,{ }^{*} p<0.05$ versus control, ${ }^{\dagger} p<0.05$ versus control CLP mice, and $p<0.01$ versus control and CRP non-CLP mice. CRP, C-reactive protein; CLP, murine cecal ligation and puncture; PECs, peritoneal exudate cells. 


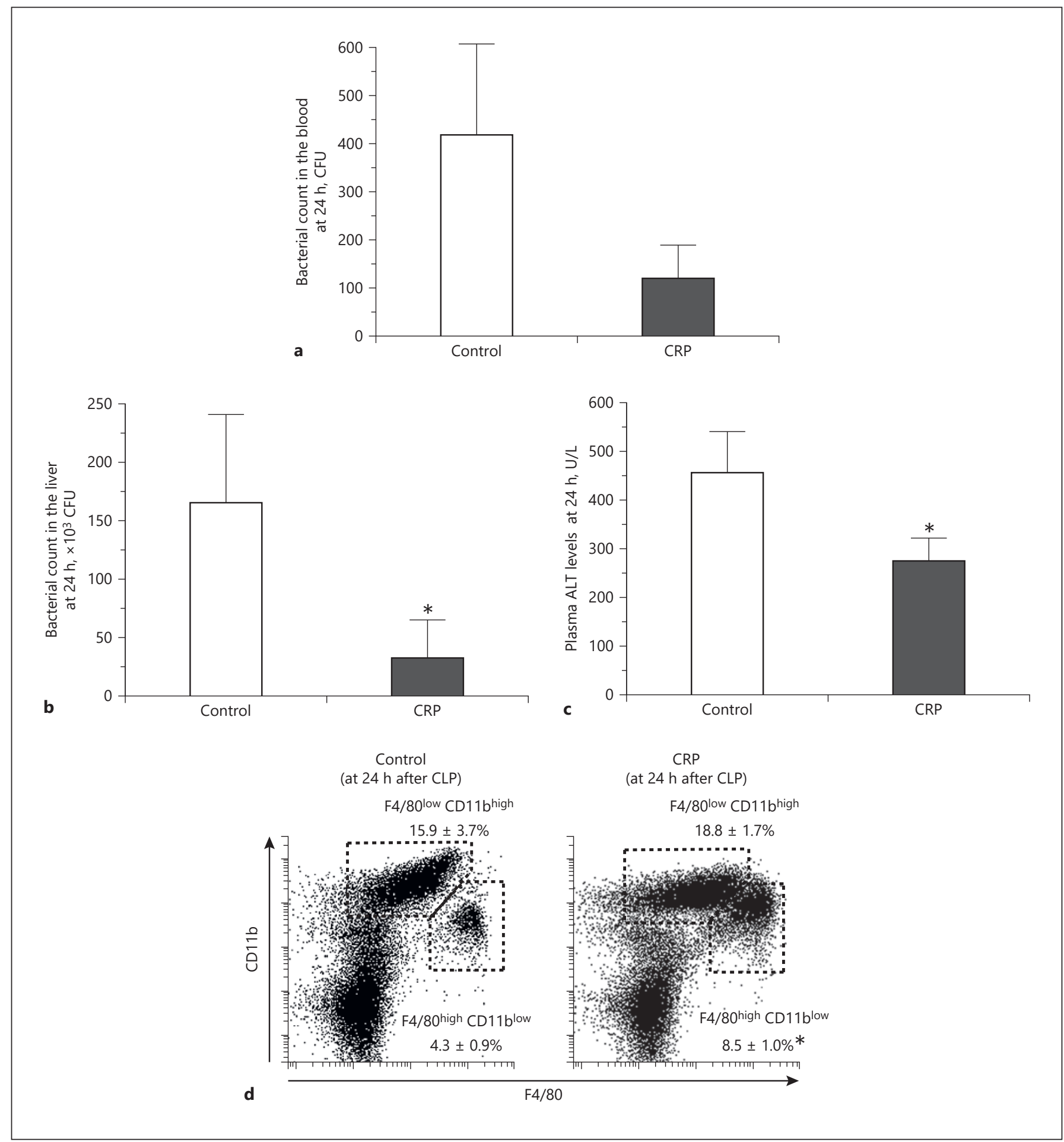

Fig. 2. The effect of posttreatment with synthetic CRP on bacterial propagation in the blood (a) and liver (b), plasma ALT levels (c), and proportion of Kupffer cells and monocyte-derived macrophages in the liver MNCs (d) at $24 \mathrm{~h}$ after CLP. Mice were treated with synthetic CRP or saline $1 \mathrm{~h}$ after CLP. Bacterial counts in the blood (a) and liver (b) and plasma ALT levels (c) were examined $24 \mathrm{~h}$ after CLP. The proportion of F4/80 $0^{\text {high }} \mathrm{CD} 11 \mathrm{~b}^{\text {low }}$ Kupffer cells and $\mathrm{F} 4 / 80^{\text {low }} \mathrm{CD} 11 \mathrm{~b}^{\text {high }}$ monocyte-derived macrophages, which are both surrounded by dotted lines, in the liver MNCs was also examined at $24 \mathrm{~h}(\mathbf{d})$. Data are shown as the mean \pm SE from 5 mice in each group. Representative data are shown with similar results (d). ${ }^{*} p<0.05$ versus control. MNCs, mononuclear cells; CRP, Creactive protein; CLP, murine cecal ligation and puncture; ALT, alanine aminotransferase. 


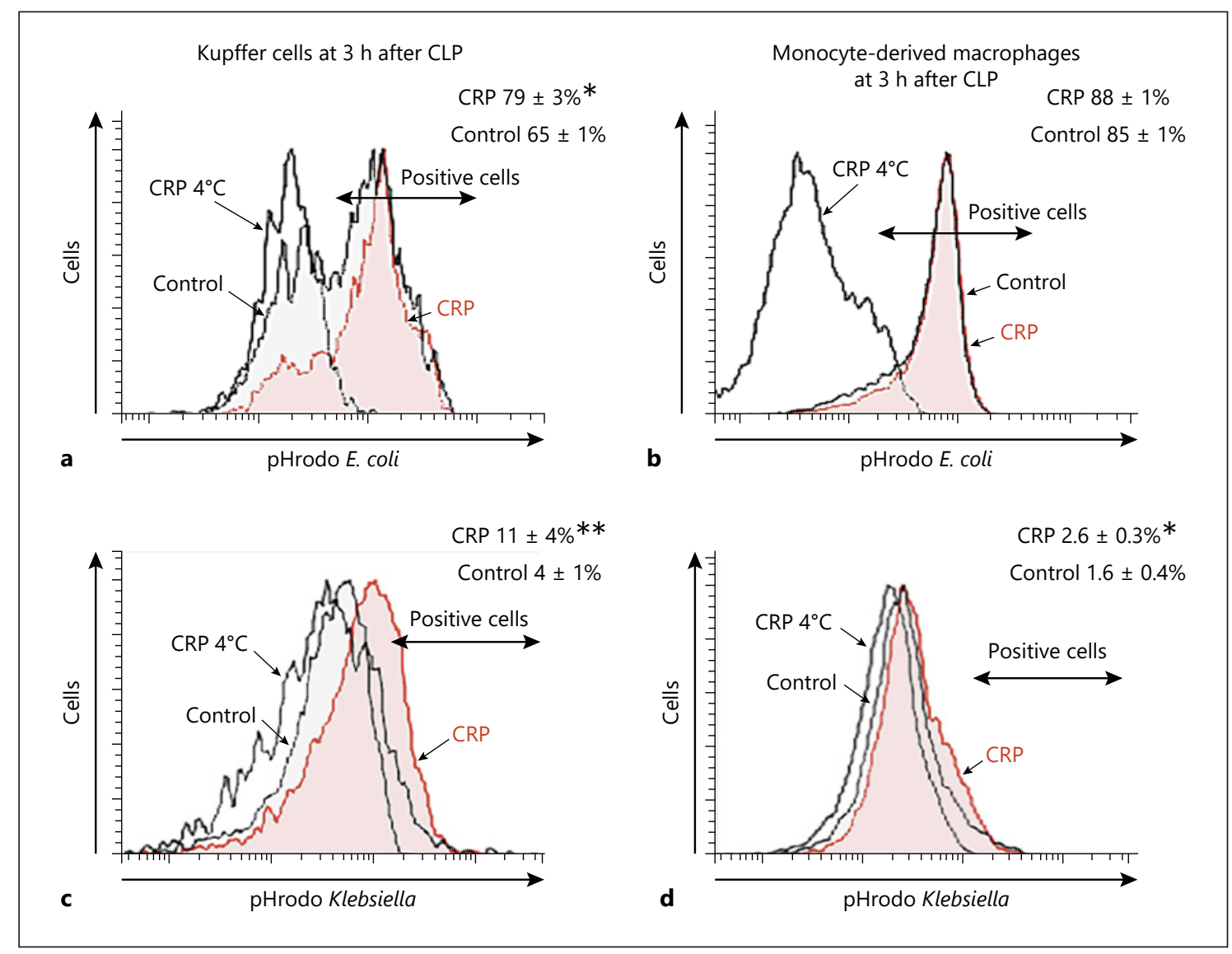

Fig. 3. The effect of synthetic CRP posttreatment on the phagolysosomal activity of Kupffer cells and monocyte-derived liver macrophages against pHrodo E. coli $(\mathbf{a}, \mathbf{b})$ or K. pneumoniae $(\mathbf{c}, \mathbf{d})$ at $3 \mathrm{~h}$ after CLP. Liver MNCs were obtained from the CRP-treated and control mice at $3 \mathrm{~h}$ after CLP and coincubated with pHrodo $E$. coli or pHrodo K. pneumoniae for $1 \mathrm{~h}$ at $37^{\circ} \mathrm{C}$ or $4^{\circ} \mathrm{C}$ (negative control) to examine the phagolysosomal acidification by $\mathrm{F} 4 / 80^{\text {high }}$

reduced the total number of PECs at $24 \mathrm{~h}$ after CLP in both CRP-treated and control mice (online suppl. Fig. 2). It almost completely deleted the Ly6 $\mathrm{C}^{-}$peritonealresident macrophages in the PECs of both CRP and control mice $(<0.02 \%$ in PECs of both mice). Clodronate treatment also mildly reduced the $\mathrm{Ly}_{6} \mathrm{C}^{+}$monocyte-derived macrophages but not the neutrophils in the PECs of both mice (Ly6C ${ }^{+}$macrophages: $6 \pm 1 \%$ in both CRP and control mice; neutrophils: $85 \pm 1 \%$ in CRP mice and $89 \pm 1 \%$ in control mice) (online suppl. Fig. 2). We further examined the effect of CRP treatment in untreated mice. CRP treatment tended to increase $\mathrm{PEC}$ counts in the untreated mice, in particular neutrophils and $\mathrm{Ly} 6 \mathrm{C}^{+}$monocyte-derived macrophages. In contrast, Ly6 $\mathrm{C}^{-}$peritoneal-resident macro-

Posttreatment with Synthetic CRP for Murine Bacterial Peritonitis
CD11b ${ }^{\text {low }}$ Kupffer cells (a, c) and F4/80 ${ }^{\text {low }}$ CD $11 b^{\text {high }}$ monocytederived macrophages $(\mathbf{b}, \mathbf{d})$. The proportion of positive cells (indicated by bidirectional arrows) shown is the mean \pm SE from 4 mice in each group. Representative data are shown with similar results. ${ }^{* *} p<0.01$ and ${ }^{*} p<0.05$ versus control. MNCs, mononuclear cells; CRP, C-reactive protein; CLP, murine cecal ligation and puncture.

phages tended to be decreased, albeit not to a significant degree (Fig. 1c).

\section{Synthetic CRP Augmented the Phagolysosomal}

Acidification against E. coli by PECs in CLP Mice

We then examined the phagolysosomal activity of PECs at $24 \mathrm{~h}$ after CLP in mice using a pHrodo E. coli assay. However, both CRP-treated and control mice already showed substantial acidification of $E$. coli by PECs at $24 \mathrm{~h}$ (online suppl. Fig. 3). We next examined the early-phase reaction of PECs to synthetic CRP. PECs were obtained $1 \mathrm{~h}$ after CLP (at the time point of CRP treatment) and incubated with or without synthetic CRP followed by pHrodo E. coli coincubation. In vitro CRP stimulation significantly enhanced the phagolysosomal 
Table 1. TNF and IFN- $\gamma$ levels in the plasma and peritoneal lavage fluid in CLP mice

\begin{tabular}{|c|c|c|c|}
\hline Variables & $\begin{array}{l}\text { CRP-treated mice } \\
(n=5)\end{array}$ & $\begin{array}{l}\text { Control mice } \\
(n=5)\end{array}$ & $\begin{array}{l}\text { Untreated normal mice } \\
(n=4)\end{array}$ \\
\hline \multicolumn{4}{|l|}{ TNF levels, $p g / m L$} \\
\hline Plasma at $3 \mathrm{~h}$ & $0.7 \pm 0.5$ & $0.5 \pm 0.3$ & Not detected \\
\hline Plasma at $24 \mathrm{~h}$ & $75 \pm 64$ & $46 \pm 21$ & Not detected \\
\hline Peritoneal lavage fluid at $24 \mathrm{~h}$ & $50 \pm 10$ & $54 \pm 19$ & $9 \pm 14^{*}$ \\
\hline \multicolumn{4}{|l|}{ IFN- $\gamma$ levels, $p g / m L$} \\
\hline Plasma at $3 \mathrm{~h}$ & Not detected & Not detected & Not detected \\
\hline Plasma at $24 \mathrm{~h}$ & $13 \pm 9$ & $21 \pm 19$ & Not detected \\
\hline Peritoneal lavage fluid at $24 \mathrm{~h}$ & $14 \pm 7$ & $11 \pm 2$ & $6 \pm 2$ \\
\hline
\end{tabular}

acidification against E. coli by PECs of CLP mice (Fig. 1d).

\section{Synthetic CRP Increased the Proportion of Kupffer Cells at $24 \mathrm{~h}$ after CLP in Mice}

The current CLP procedure induced severe bacterial peritonitis in mice ( $10 \%$ survival), so bacteria spread into the systemic circulation. At $24 \mathrm{~h}$ after CLP, a substantial number of bacteria were observed in the blood of control mice (Fig. 2a). CRP-treated mice also showed bacteria in their blood at $24 \mathrm{~h}$, although their bacterial counts tended to be lower than those in control mice (Fig. 2a). Since CRP treatment was suspected to potentially reduce bacterial propagation in murine bodies, we next examined the bacterial propagation in the murine liver after CLP. CRP posttreatment markedly reduced the viable bacterial count in the liver $24 \mathrm{~h}$ after CLP and also reduced plasma ALT levels at $24 \mathrm{~h}$ (Fig. 2b, c).

We then examined the effect of CRP treatment on Kupffer cells and monocyte-derived liver macrophages in the CLP mice. CRP treatment significantly increased the proportion of Kupffer cells (F4/80 ${ }^{\text {high }} \mathrm{CD} 11 b^{\text {low }}$ subset) at $24 \mathrm{~h}$ after CLP compared with control mice, although CRP treatment did not affect the proportion of monocyte-derived macrophages (F4/80 low $\mathrm{CD} 11 \mathrm{~b}^{\text {high }}$ subset) in the liver (Fig. 2d). No significant difference in the number of liver MNCs was observed between the CRP-treated and control mice at $24 \mathrm{~h}$ after CLP (CRPtreated mice: $2.7 \pm 0.7 \times 10^{6}$ cells vs. control mice: $2.5 \pm$ $0.7 \times 10^{6}$ cells).

\section{Synthetic CRP Enhanced Phagolysosomal}

Acidification of Kupffer Cells against E. coli as well as Capsulated K. pneumoniae at $3 \mathrm{~h}$ after CLP in Mice

We next examined the phagolysosomal activity of these liver macrophages in CLP mice. Not only Kupffer cells but also monocyte-derived liver macrophages showed potent phagolysosomal acidification in both CRP-treated and control mice at $24 \mathrm{~h}$ after CLP, and no significant differences in the phagolysosomal activities of these liver macrophages were observed between the CRPtreated and control mice (online suppl. Fig. 4a, b).

We then focused on the early phase of CLP. Kupffer cells/macrophages were obtained from the mice at $3 \mathrm{~h}$ after CLP ( $2 \mathrm{~h}$ later CRP treatment). No significant difference in the proportion of Kupffer cells or monocytederived macrophages was observed yet between the CRP-treated and control mice at $3 \mathrm{~h}$ (not shown). However, interestingly, CRP treatment significantly enhanced the phagolysosomal acidification of Kupffer cells against E. coli (Fig. 3a). In contrast, CRP treatment did not affect the phagolysosomal activity of the monocyte-derived liver macrophages, although those macrophages in both groups showed potent phagolysosomal activities against E. coli (Fig. 3b). Posttreatment with synthetic CRP may preferentially induce Kupffer cells to increase their numbers and bactericidal activity, thereby enhancing the bacterial clearance in the liver of CLP mice.

CRP is well-known as an opsonizing factor [4]. We then examined the opsonizing effect of CRP treatment 
on the digestive activity of capsulated $K$. pneumoniae in liver macrophages similarly obtained from mice at $3 \mathrm{~h}$ after CLP. Interestingly, CRP treatment potently augmented phagolysosomal acidification by Kupffer cells (Fig. 3c) and also mildly increased it by monocyte-derived macrophages (Fig. $3 \mathrm{~d}$ ), suggesting that CRP-involved opsonization contributes to the enhanced digestion of capsulated microorganisms (e.g., $K$. pneumoniae) by liver macrophages, in particular, Kupffer cells.
Synthetic CRP Increased Tissue TNF Levels in the Liver at $24 \mathrm{~h}$ after CLP in Mice

We next examined the effect of CRP treatment on the cytokine secretions in CLP mice. CRP-treated mice showed a tendency toward higher plasma TNF levels at $24 \mathrm{~h}$ after CLP compared with control mice (Table 1). However, no significant difference in the TNF levels of the peritoneal lavage fluid was observed at $24 \mathrm{~h}$ after CLP between the CRPtreated and control mice, although both mice showed significantly higher TNF levels in the peritoneal lavage fluid
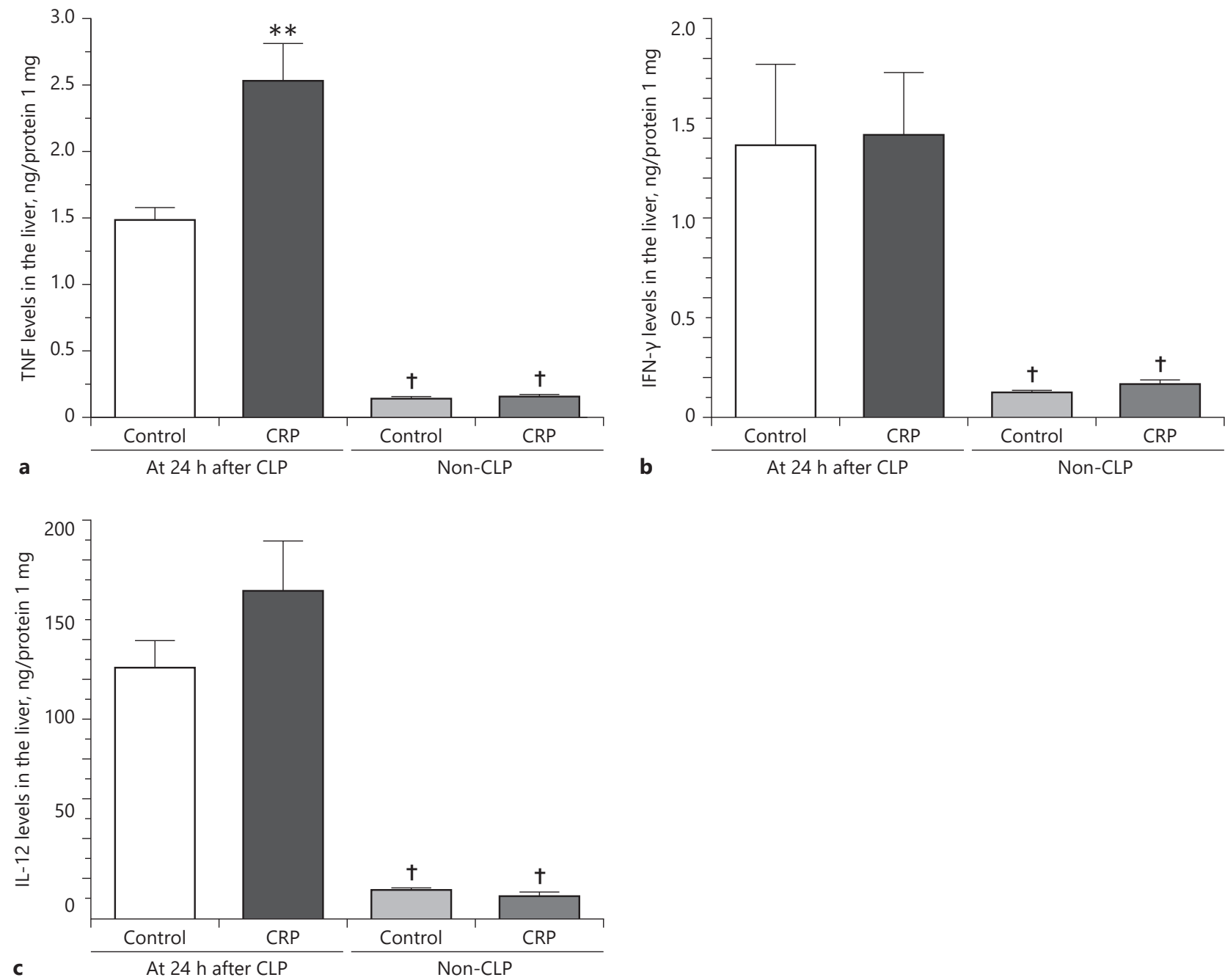

Fig. 4. The effect of synthetic CRP posttreatment on the tissue TNF (a), IFN- $\gamma$ (b), and IL-12 (c) levels in the liver at $24 \mathrm{~h}$ after CLP. The livers were obtained from the CRP-treated and control mice at $24 \mathrm{~h}$ after CLP as well as from the CRP-treated and control non-CLP mice to examine the tissue TNF (a), IFN- $\gamma(\mathbf{b})$, and
IL-12 (c) levels. Data are shown as the mean \pm SE from 5 mice in each group. ${ }^{* *} p<0.01$ versus others. ${ }^{\dagger} p<0.01$ versus CRP-treated and control CLP mice. CRP, C-reactive protein; CLP, murine cecal ligation and puncture. 
than untreated normal mice (Table 1). Regarding IFN- $\gamma$ secretion, no significant differences in the IFN- $\gamma$ levels were observed in the plasma or peritoneal lavage fluid at $24 \mathrm{~h}$ after CLP between the CRP and control mice (Table 1).

We examined the tissue cytokine levels in the murine liver at $24 \mathrm{~h}$ after CLP. CRP-treated CLP mice showed significantly higher tissue TNF levels in the liver than that of the control CLP mice, although these TNF levels in both CRP-treated and control CLP mice were markedly higher than in the CRP/control non-CLP mice (Fig. 4a). In contrast, no significant difference in the IFN- $\gamma$ levels was observed in the liver tissue at $24 \mathrm{~h}$ after CLP between the CRP-treated and control CLP mice, although the IFN- $\gamma$ levels were also markedly higher than those in the $\mathrm{CRP} /$ control non-CLP mice (Fig. $4 \mathrm{~b}$ ). We examined the liver levels of IL-12, which are known to induce IFN- $\gamma$ production in the liver. No significant difference in the IL-12 levels was observed at $24 \mathrm{~h}$ in the liver tissue between the CRP-treated and control CLP mice (Fig. 4c).

\section{CRP Treatment Increased the Intracellular TNF}

Expression of the E. coli-Phagocytosing Kupffer Cells at 3 h after $C L P$

We examined the effect of CRP treatment on the TNF production of Kupffer cells. Liver MNCs obtained $3 \mathrm{~h}$ after CLP ( $2 \mathrm{~h}$ later CRP treatment) were coincubated with pHrodo E. coli to examine the intracellular TNF of the E. coli-phagocytosing and nonphagocytosing liver macrophages. CRP treatment significantly increased the intracellular TNF expression in the E. coli-phagocytosing Kupffer cells (Fig. 5a, mean flow intensity; $77 \pm 8 \times 10^{3}$ vs. $\left.52 \pm 2 \times 10^{3}, p<0.05\right)$. In contrast, nonphagocytosing Kupffer cells did not show any evident intracellular TNF in either CRP-treated or control mice (Fig. 5b). Regarding the monocyte-derived liver macrophages, not only E. coliphagocytosing but also nonphagocytosing macrophages

Fig. 5. The effect of synthetic CRP posttreatment on the intracellular TNF expression of $E$. coli-phagocytosing or nonphagocytosing Kupffer cells (a, b) and monocyte-derived liver macrophages (c, d) at $3 \mathrm{~h}$ after CLP. The liver MNCs were obtained from the CRP-treated and control mice at $3 \mathrm{~h}$ after CLP and coincubated with pHrodo E. coli for $1 \mathrm{~h}$ to examine the intracellular TNF expression of $E$. coli-phagocytosing F4/80 high $C D 11 b^{\text {low }}$ Kupffer cells (a) and nonphagocytosing cells (b) as well as E. coli-phagocytosing $\mathrm{F} 4 / 80^{\text {low }} \mathrm{CD} 11 \mathrm{~b}^{\text {high }}$ monocyte-derived macrophages (c) and nonphagocytosing cells (d). The MFI shown is the mean \pm SE from 4 mice in each group. Representative data are shown with similar results. ${ }^{*} p<0.05$ versus control. MNCs, mononuclear cells; CRP, C-reactive protein; CLP, murine cecal ligation and puncture; MFI, mean fluorescence intensity. showed potent intracellular TNF expression, but CRP treatment did not affect the TNF expression (Fig. 5c, d). CRP treatment may increase the TNF production in bacteria-phagocytosing Kupffer cells but not in monocytederived liver macrophages (regardless of phagocytosis).
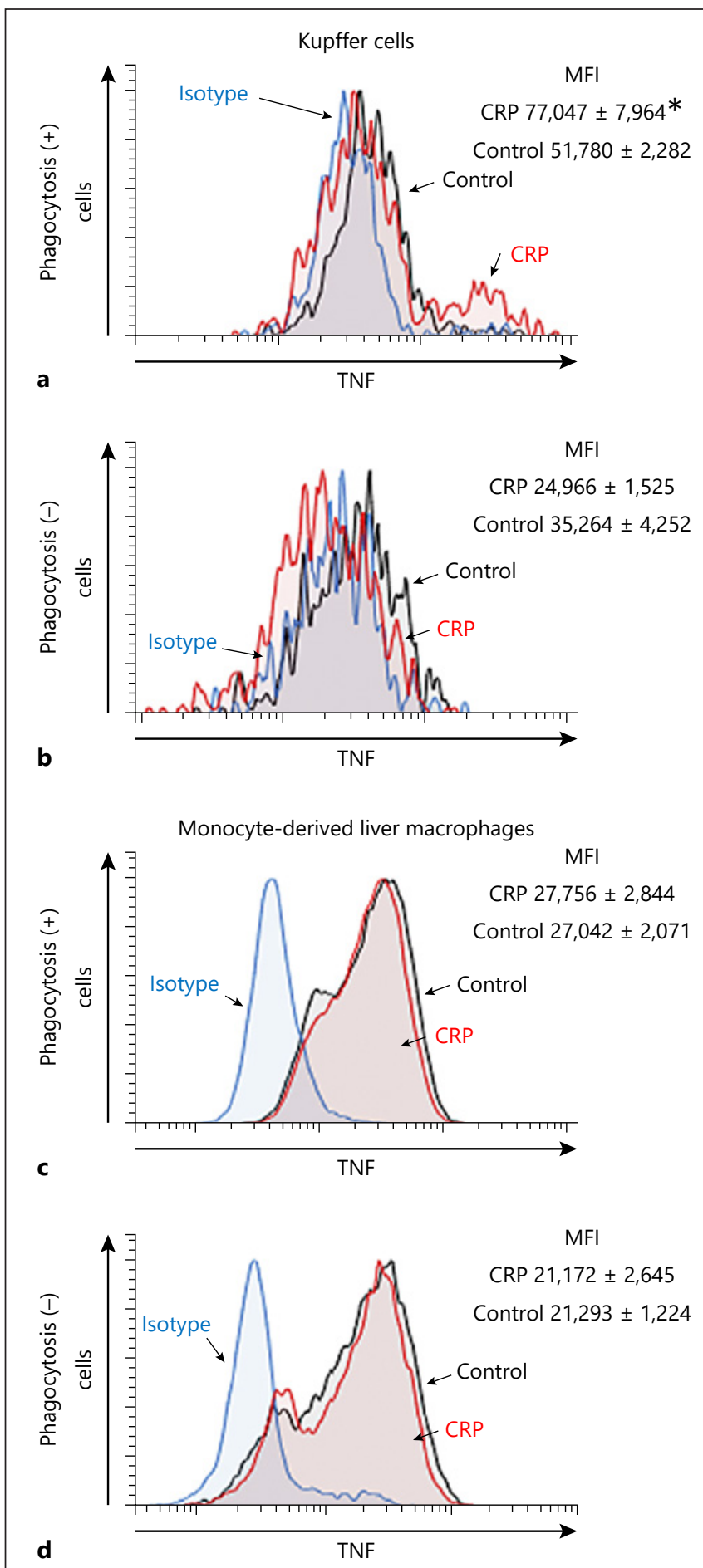


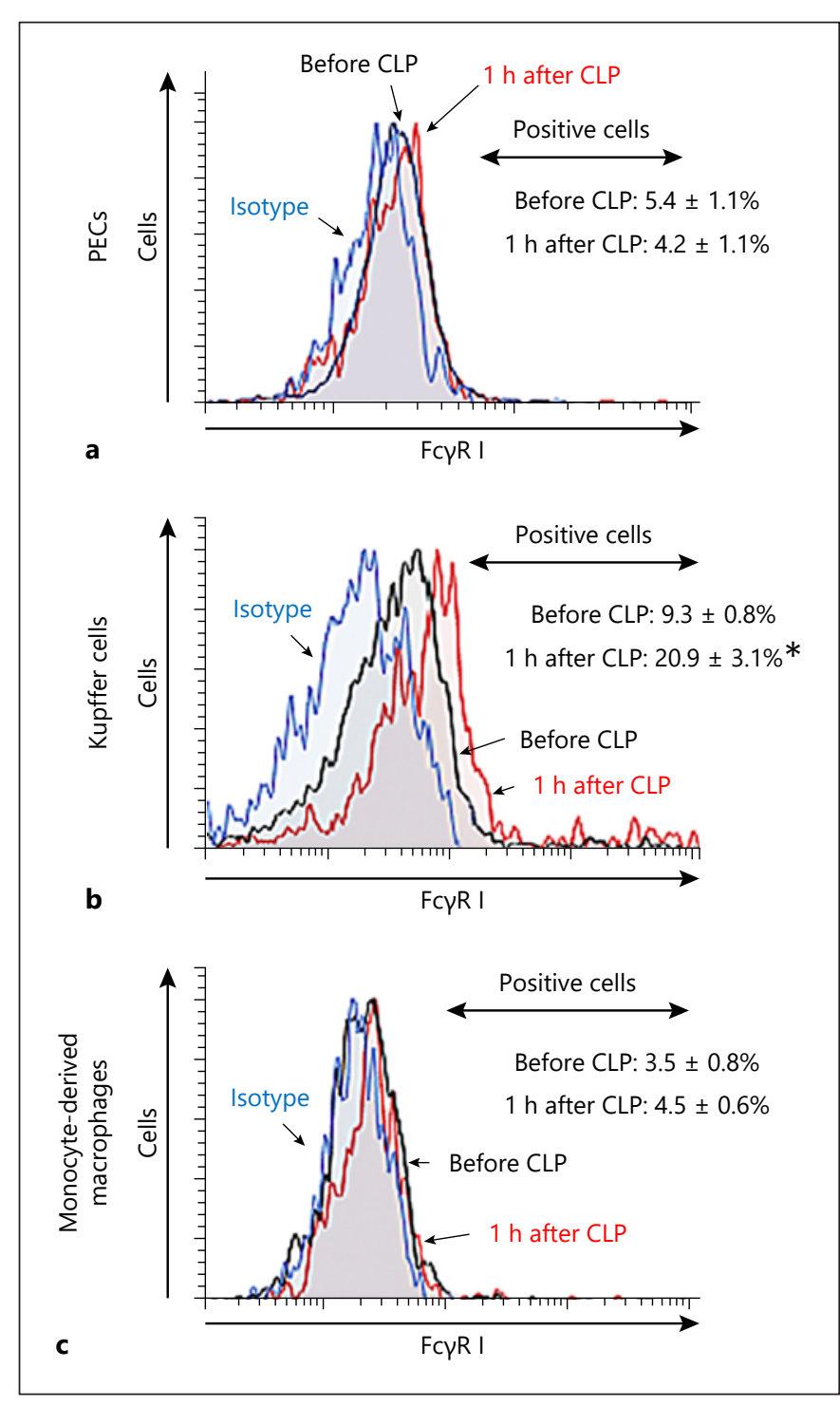

Fig. 6. The effect of synthetic CRP posttreatment on the Fc $\gamma$ RI expression of PECs (a), Kupffer cells (b), and monocyte-derived liver macrophages (c) in mice. PECs and liver MNCs were obtained from the untreated normal mice (before CLP) and the mice $1 \mathrm{~h}$ after CLP to examine the Fc $\gamma$ RI expression of PECs (a), F4/80 high CD $11 b^{\text {low }}$ Kupffer cells (b), and F4/80 low CD $11 b^{\text {high }}$ monocyte-derived macrophages (c). The proportion of positive cells (indicated by bidirectional arrows) shown is the mean \pm SE from 4 mice in each group. Representative data are shown with similar results. ${ }^{*} p<0.05$ versus before CLP. MNCs, mononuclear cells; CRP, Creactive protein; CLP, murine cecal ligation and puncture; PECs, peritoneal exudate cells.

\section{Kupffer Cells Markedly Increased the Fc $\gamma$ RI}

Expression at 1 h after CLP

Through Fc $\gamma$ RI, CRP induces macrophage activation, particularly with regard to their phagocytic function [21,
$22]$. We examined the $\mathrm{Fc} \gamma \mathrm{RI}$ expression by peritoneal and liver macrophages. Fc $\gamma$ RI was weakly expressed on a few peritoneal macrophages (approximately 5\%) in untreated normal mice (before CLP), and the Fc $\gamma \mathrm{RI}$ expression had not changed by $1 \mathrm{~h}$ after CLP (at the time point of CRP treatment) (Fig. 6a). Kupffer cells in untreated normal mice, by contrast, showed substantial Fc $\gamma$ RI expression, and this expression was significantly increased at $1 \mathrm{~h}$ after CLP (Fig. 6b). Monocyte-derived liver macrophages weakly expressed $\mathrm{Fc} \gamma \mathrm{RI}$ both when untreated and at $1 \mathrm{~h}$ after CLP (<5\%) (Fig. 6c). Synthetic CRP may activate the phagocytic activity of Kupffer cells via the upregulation of $\mathrm{Fc} \gamma \mathrm{RI}$ on their surface in CLP mice.

\section{Depletion of Kupffer Cells Abolished the Beneficial \\ Effect of Synthetic CRP Treatment on the Survival of CLP Mice}

To examine the role of Kupffer cells in CRP-treated CLP mice, Kupffer cells were depleted in mice using clodronate liposomes, and thereafter, the mice received CLP followed by CRP treatment. Clodronate liposomes in the murine liver almost completely depleted F4/80 high CD$11 b^{\text {low }}$ cells, which are Kupffer cells, but not F4/80 low CD11b $b^{\text {high }}$ monocyte-derived macrophages (Fig. 7a). As expected, all Kupffer cell-depleted mice died within $24 \mathrm{~h}$ after CLP (Fig. 7b). Notably, CRP treatment did not increase the survival rate of Kupffer cell-depleted mice $(0 \%$ survival) (Fig. 7b), suggesting that the improving effect of CRP posttreatment on the survival of CLP mice was dependent on Kupffer cells.

\section{Discussion}

Posttreatment with synthetic CRP, which was done at $1 \mathrm{~h}$ after CLP, markedly enhanced the bacterial clearance in the liver (Fig. 2b), thereby increasing the survival of CLP mice (Fig. 1a). Synthetic CRP treatment increased the number of Kupffer cells and augmented their phagolysosomal activity against $E$. coli and capsulated $K$. pneumoniae in CLP mice (Fig. 2d, 3a, c). E. coli and K. pneumoniae are representative enterobacteria and play important roles in bacterial peritonitis caused by intestinal perforation [23]. The opsonizing effect of CRP may contribute the effective elimination of capsulated $K$. pneumoniae by Kupffer cells in the CLP mice (Fig. 3c). Consistently, the depletion of Kupffer cells in mice abolished this beneficial effect of synthetic CRP on the murine survival after bacterial peritonitis (Fig. $7 \mathrm{~b}$ ), suggesting that synthetic CRP quantitatively and qualitatively acti- 


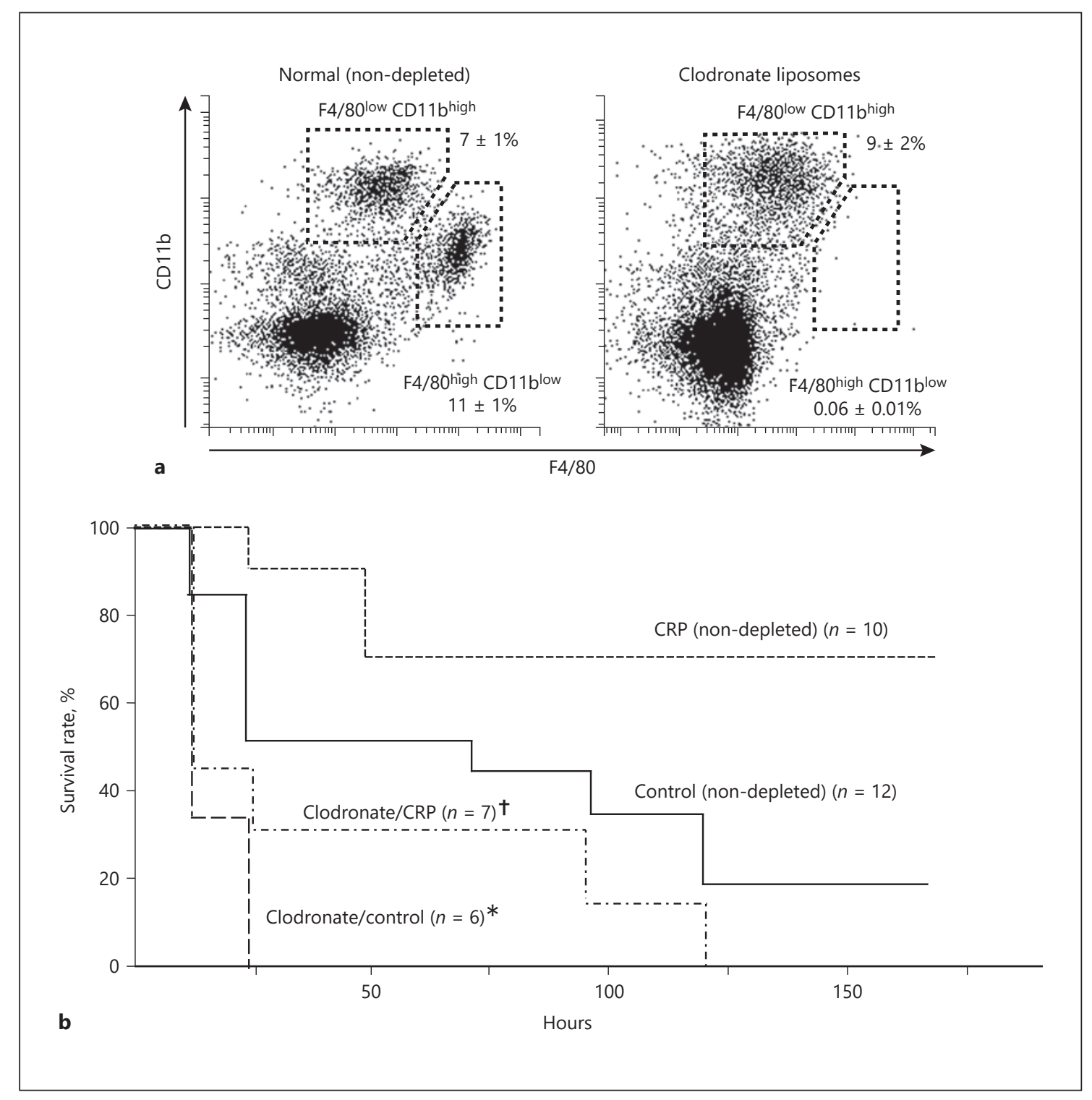

Fig. 7. The effect of clodronate liposomes on the murine liver MNCs (a) and the survival of CRP-treated CLP mice (b). Liver MNCs were obtained from mice 2 days after the intravenous administration of clodronate liposomes or from untreated normal mice to examine the proportion of F4/80 high $\mathrm{CD} 11 \mathrm{~b}^{\text {low }}$ Kupffer cells and F4/80 $0^{\text {low }} \mathrm{CD} 11 \mathrm{~b}^{\text {high }}$ monocyte-derived macrophages (a). The proportions of F4/80 high $C D 11 b^{\text {low }}$ Kupffer cells and F4/80 low CD11b ${ }^{\text {high }}$ monocyte-derived macrophages, which are both sur-

vates Kupffer cells, thereby improving murine bacterial peritonitis.

Kupffer cells have more potent phagocytic activity than monocyte-derived liver macrophages [10-12]. They substantially express $\mathrm{F} c \gamma \mathrm{RI}$, which is a ligand of CRP that stimulates their phagocytic activity $[21,22]$. Importantly, rounded by dotted lines, in the liver MNCs are shown as the mean \pm SE from 3 mice in each group. Representative data are shown with similar results. Clodronate liposome-treated mice and untreated normal mice received CLP followed by synthetic CRP or saline treatment to examine the survival (b). ${ }^{*} p<0.05$ versus control (nondepleted) mice and ${ }^{\dagger} p<0.01$ versus CRP (nondepleted) mice. MNCs, mononuclear cells; CRP, C-reactive protein; CLP, murine cecal ligation and puncture.

the FcyRI expression on Kupffer cells was further increased after CLP (Fig. 6b), which may have contributed to the efficacy of posttreatment with synthetic CRP even after the occurrence of bacterial peritonitis.

However, by contrast, synthetic CRP did not significantly affect monocyte-derived liver macrophages, which 
did not strongly express Fc $\gamma$ RI on their surface (Fig. 6c). These monocyte-derived macrophages did exert a certain degree of phagocytic activity (Fig. 3b) and showed a potent TNF-producing capability (Fig. 5c, d) in CLP mice. However, monocyte-derived macrophages alone (by depletion of Kupffer cells) failed to save mice beyond $24 \mathrm{~h}$ after CLP (Fig. 7a, b), indicating that Kupffer cells play a crucial role in the elimination of bacteria in the liver [2,3]. Namely, activation of Kupffer cells by synthetic CRP may be effective for bacterial elimination in sepsis.

Peritoneal macrophages also play important roles in managing bacterial peritonitis [24]. Synthetic CRP may augment the bactericidal activity of PECs, resulting in a reduction in bacterial counts in the peritoneal cavity of CLP mice (Fig. 1b-d). At $1 \mathrm{~h}$ after CLP in mice, neutrophils did not increase in the peritoneal cavity yet, and in vitro CRP-induced E. coli-phagocytosing cells were mainly peritoneal-resident macrophages (data not shown). Nevertheless, the opsonizing effect of CRP on PECs, including neutrophils, may also possibly contribute to the enhancement of bacterial killing in the peritoneal cavity of CLP mice (Fig. 1b, c). We should address this issue in a future study. However, when the bacteria spill over into the systemic circulation, the liver plays a crucial role in bacterial clearance for the host $[2,3]$. The activation of Kupffer cells by synthetic CRP may play a key role in hosts surviving severe bacterial peritonitis.

Macrophages have 2 fundamental functions: phagocytosis and the production of cytokines, such as TNF [8]. In our previous study, synthetic CRP potently reduced the elevation of plasma TNF after lipopolysaccharide (LPS) challenge but conversely tended to increase the plasma TNF levels after E. coli challenge [6]. Phagocytosis of challenged bacteria by macrophages may be involved in the sustained TNF production in CRP-treated mice [6]. In the current study, synthetic CRP treatment also tended to increase the plasma TNF levels after CLP in mice, and interestingly, it significantly increased the tissue TNF levels in the liver of CLP mice (Fig. 4a). In addition, synthetic CRP increased the intracellular TNF expression in the E. coli-phagocytosing Kupffer cells (Fig. 5a). Synthetic CRP may stimulate the TNF production by Kupffer cells when these cells phagocytose bacteria in the liver.

Monocyte-derived liver macrophages have a more potent TNF-producing capability than Kupffer cells [11, 12]. These macrophages in CLP mice, both E. coli-phagocytosing and nonphagocytosing ones, showed strong intracellular TNF production (Fig. 5c, d). Nevertheless, synthetic CRP treatment failed to affect the intracellular TNF expression in these macrophages, regardless of phagocytosis ability (Fig. 5c, d), which expressed a weak Fc $\gamma$ RI, a ligand of CRP (Fig. 6c). Excessively secreted TNF may be harmful for hosts with sepsis, although it is essential for the host defense against bacteria [25]. According to our previous study, the exaggerated secretion of TNF after bacterial challenge may involve the preferential production of TNF by monocyte-derived macrophages [11]. Although synthetic CRP has the potential to reduce LPS-induced TNF secretion by macrophages [6], synthetic CRP did not reduce TNF production by these monocyte-derived macrophages in the current CLP model (Fig. 5c, d). However, we confirmed that coincubation of synthetic CRP significantly reduced the in vitro LPS-stimulated TNF production of monocyte-derived liver macrophages, although synthetic CRP did not affect the LPS-stimulated TNF production by Kupffer cells (online suppl. Fig. 5). The difference in stimulation by LPS and bacteria may influence this discrepancy in the TNF response of monocyte-derived macrophages to synthetic CRP. Further studies will be needed to address this issue.

Finally, it should be noted that when we treated the mice with CRP at $3 \mathrm{~h}$ after CLP, it was not effective (20\% survival). The current murine CLP model may be critically severe because more than half of the control mice died within $24 \mathrm{~h}$ after CLP, and their mortality eventually reached approximately $90 \%$ (Fig. 1a). Therefore, bacterial peritonitis had presumably already progressed to a severe condition in mice, even at $3 \mathrm{~h}$ after CLP. Although posttreatment with CRP may be clinically useful and attractive, it should be performed as soon as possible after the occurrence of infection.

\section{Statement of Ethics}

The experimental protocol of the present study was approved by the Institutional Ethics Committee of Animal Care and Experimentation, National Defense Medical College Japan (Permission No. 17049), and Nippon Medical School Japan (Permission No. 27-120). This study was performed strictly according to the ARRIVE guidelines [26].

\section{Conflict of Interest Statement}

The authors have no conflicts of interest. 


\section{Funding Sources}

This work was supported in part by JSPS KAKENHI Grant No. 18H02907 (M.K. and S.S.) and 16K11424 (A.M. and M.M.).

\section{Author Contributions}

Conceived and designed the experiments: M.K. Performed the experiments: M.K., S.I., T.I., K.S., R.Y., R.T., and K.K. Analyzed the data: M.K., A.K., M.N., and H.N. Contributed reagents/materials/analysis tools: M.K., A.M., and M.M. Wrote the manuscript: M.K. and S.S.

\section{References}

1 Kinoshita M, Miyazaki H, Ono S, Seki S. Immunoenhancing therapy with interleukin- 18 against bacterial infection in immunocompromised hosts after severe surgical stress. J Leukoc Biol. 2013 May;93(5):689-98.

2 Bilzer M, Roggel F, Gerbes AL. Role of Kupffer cells in host defense and liver disease. Liver Int. 2006 Dec;26(10):1175-86.

3 Ashare A, Monick MM, Powers LS, Yarovinsky T, Hunninghake GW. Severe bacteremia results in a loss of hepatic bacterial clearance. Am J Respir Crit Care Med. 2006 Mar 15; 173(6):644-52.

$4 \mathrm{Du}$ Clos TW. Function of C-reactive protein. Ann Med. 2000 May;32(4):274-8.

5 Barna BP, Thomassen MJ, Maier M, Medendorp SV, Tubbs RR, Chiang T, et al. Combination therapy with a synthetic peptide of Creactive protein and interleukin 2: augmented survival and eradication of pulmonary metastases. Cancer Immunol Immunother. 1994 Jan;38(1):38-42.

6 Inatsu A, Kinoshita M, Nakashima H, Shimizu J, Saitoh D, Tamai S, et al. Novel mechanism of C-reactive protein for enhancing mouse liver innate immunity. Hepatology. 2009 Jun;49(6):2044-54.

7 Sato A, Nakashima H, Kinoshita M, Nakashima M, Ogawa Y, Shono S, et al. The effect of synthetic C-reactive protein on the in vitro immune response of human PBMCs stimulated with bacterial reagents. Inflammation. 2013 Aug;36(4):781-92.

8 Murray RZ, Kay JG, Sangermani DG, Stow JL. A role for the phagosome in cytokine secretion. Science. 2005 Dec 2;310(5753):1492-5.

9 Hubbard WJ, Choudhry M, Schwacha MG, Kerby JD, Rue LW 3rd, Bland KI, et al. Cecal ligation and puncture. Shock. 2005 Dec; 24(Suppl 1):52-7.

10 Klein I, Cornejo JC, Polakos NK, John B, Wuensch SA, Topham DJ, et al. Kupffer cell heterogeneity: functional properties of bone marrow derived and sessile hepatic macrophages. Blood. 2007 Dec 1;110(12):4077-85.
11 Kinoshita M, Uchida T, Sato A, Nakashima M, Nakashima H, Shono S, et al. Characterization of two F4/80-positive Kupffer cell subsets by their function and phenotype in mice. J Hepatol. 2010 Nov;53(5):903-10.

12 Ikarashi M, Nakashima H, Kinoshita M, Sato A, Nakashima M, Miyazaki H, et al. Distinct development and functions of resident and recruited liver Kupffer cells/macrophages. J Leukoc Biol. 2013 Aug 20;94(6):1325-36.

13 van de Laar L, Saelens W, De Prijck S, Martens L, Scott CL, Van Isterdael G, et al. Yolk sac macrophages, fetal liver, and adult monocytes can colonize an empty niche and develop into functional tissue-resident macrophages. Immunity. 2016 Apr 19;44(4):755-68.

14 Ami K, Kinoshita M, Yamauchi A, Nishikage T, Habu Y, Shinomiya N, et al. IFN-gamma production from liver mononuclear cells of mice in burn injury as well as in postburn bacterial infection models and the therapeutic effect of IL-18. J Immunol. 2002 Oct 15;169(8): 4437-42.

15 Fujie T, Kinoshita M, Shono S, Saito A, Okamura Y, Saitoh D, et al. Sealing effect of a polysaccharide nanosheet for murine cecal puncture. Surgery. 2010 Jul;148(1):48-58.

16 Kinoshita M, Shinomiya N, Ono S, Tsujimoto H, Kawabata T, Matsumoto A, et al. Restoration of natural IgM production from liver B cells by exogenous IL-18 improves the survival of burn-injured mice infected with Pseudomonas aeruginosa. J Immunol. 2006 Oct 1; 177(7):4627-35.

17 Kinoshita M, Miyazaki H, Nakashima H, Nakashima $M$, Nishikawa $M$, Ishikiriyama $T$, et al. In vivo lipopolysaccharide tolerance recruits CD11b+ macrophages to the liver with enhanced bactericidal activity and low tumor necrosis factor-releasing capability, resulting in drastic resistance to lethal septicemia. J Innate Immun. 2017;9(5):493-510.
18 Davies LC, Jenkins SJ, Allen JE, Taylor PR. Tissue-resident macrophages. Nat Immunol. 2013 Oct;14(10):986-95.

19 Nakao M, Kim K, Nagase K, Grainger DW, Kanazawa H, Okano T. Phenotypic traits of mesenchymal stem cell sheets fabricated by temperature-responsive cell culture plate: structural characteristics of MSC sheets. Stem Cell Res Ther. 2019;10(1):353.

20 Amako K, Meno Y, Takade A. Fine structures of the capsules of Klebsiella pneumoniae and Escherichia coli K1. J Bacteriol. 1988 Oct; 170(10):4960-2.

21 Tron K, Manolov DE, Röcker C, Kächele M, Torzewski J, Nienhaus GU. C-reactive protein specifically binds to Fcgamma receptor type I on a macrophage-like cell line. Eur J Immunol. 2008 May;38(5):1414-22.

22 Marjon KD, Marnell LL, Mold C, Du Clos TW. Macrophages activated by C-reactive protein through $\mathrm{Fc}$ gamma RI transfer suppression of immune thrombocytopenia. J Immunol. 2009 Feb 1;182(3):1397-403.

23 Sartelli M, Catena F, Ansaloni L, Leppaniemi A, Taviloglu K, van Goor H, et al. Complicated intra-abdominal infections in Europe: a comprehensive review of the CIAO study. World J Emerg Surg. 2012 Nov 29;7(1):36.

24 Spight D, Trapnell B, Zhao B, Berclaz P, Shanley TP. Granulocyte-macrophage-colonystimulating factor-dependent peritoneal macrophage responses determine survival in experimentally induced peritonitis and sepsis in mice. Shock. 2008;30(4):434-42.

25 Chen G, Goeddel DV. TNF-R1 signaling: a beautiful pathway. Science. 2002 May 31; 296(5573):1634-5.

26 Kilkenny C, Browne WJ, Cuthill IC, Emerson $\mathrm{M}$, Altman DG. Improving bioscience research reporting: the ARRIVE guidelines for reporting animal research. J Pharmacol Pharmacother. 2010 Jun 29;1(2):94. 